\title{
Study On Oxidation of Calcium Sulfite in Wet Sintering Flue Gas Desulphurization Process
}

\author{
Zhaohui Zhang ${ }^{1,2, a}$, Jiangkai Wan ${ }^{b}$, Bailong Liu $^{c,{ }^{*}}$ and Hanlong Jiang ${ }^{d}$ \\ ${ }^{1}$ School of Metallurgical Engineering, Xi'an University of Architecture and Technology, Xi'an 710055, \\ P. R. China \\ ${ }^{2}$ Shaanxi Province Metallurgical Engineering and Technology Research Centre, Xi'an University of \\ Architecture and Technology, Xi'an 710055, P. R. China

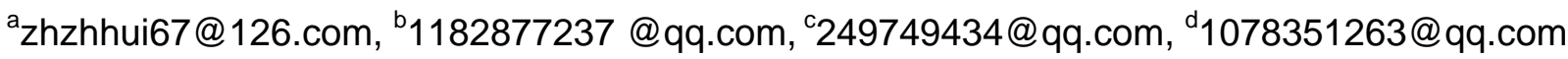

\begin{abstract}
Due to oxidation of calcium sulfite in wet sintering flue gas desulfurization process, it has difficulty in comprehensive utilization of desulfurization gypsum (DG). Based on the analysis of principle and characteristics of wet flues gas desulfurization, reasons and resolve solutions for oxidation of calcium sulfite has been put forward in this paper to provide a theoretical basis for comprehensive utilization of DG.
\end{abstract}

Keywords: Sintering flue gas, Calcium sulfite, Oxidation, Crystallization, Desulfurization

\section{Introduction}

With the enact of new environmental protection law, green innovation has gained significant popularity in metallurgical enterprises. As a typical energy-consumption alternative, metallurgical enterprises will be in an entirely new and more serious environment, especially the improvement of sulfur dioxide's emission standard which is lethal for the industry. The characteristics of sintering flue gas are as follows: large emissions; sharp change of concentration of sulfur dioxide; a high content of impurities, which makes desulfurization process more difficult. Limestone-gypsum sintering flue gas desulfurization technology is the main method of sintering flue gas desulfurization processes [1]. However, there are some drawbacks in this process: low desulfurization rate, high consumption of raw material, large energy consumption, enormous emission of DG, etc. This paper analyses oxidation mechanism of calcium sulfite to provide a theoretical basis for comprehensive utilization of DG.

\section{Principle and Characteristics of Wet Sintering Flue Gas Desulfurization Process}

The wet process is main sintering flue gas desulfurization method, which has some advantages such as easy access to raw material, perfect operating flexibility, better operational stability, etc. It uses limestone/lime as raw material, and absorbs $\mathrm{SO}_{2} / \mathrm{SO}_{3}$ under certain conditions to transform it to $\mathrm{CaSO}_{3}$ of a low solubility [2]. Furthermore, $\mathrm{CaSO}_{3}$ is oxidized to gypsum in the air for the purpose of desulfurization. In this process, the main reactions are as follows:

$$
\begin{gathered}
\mathrm{CaO} / \mathrm{CaCO}_{3}+\mathrm{SO}_{2}+\mathrm{H}_{2} \mathrm{O} \rightarrow \mathrm{CaSO}_{3}+\mathrm{CO}_{2} / \mathrm{H}_{2} \mathrm{O} \\
\mathrm{CaSO}_{3}+\mathrm{SO}_{2}+\mathrm{H}_{2} \mathrm{O} \rightarrow \mathrm{Ca}\left(\mathrm{HSO}_{3}\right)_{2} \\
2 \mathrm{CaSO}_{3}+\mathrm{O}_{2}+2 \mathrm{H}_{2} \mathrm{O} \rightarrow \mathrm{CaSO}_{4} \bullet 2 \mathrm{H}_{2} \mathrm{O} \text { (gypsum) }
\end{gathered}
$$

Just as equations above, limestone reacts with sulfur dioxide to form calcium sulfite or calcium bisulfite, and further to be oxidized as calcium sulphate dehydrate in the air. However, this oxidation process isn't smooth for sintering flue gas's characteristics of low desulfurization rate, high consumption of raw material, large energy consumption, enormous emission of DG, etc [3]. The common problems in wet sintering flue gas desulfurization process are as follows:

Lime/limestone has a low solubility. Depended on reduce of aqueous solution $\mathrm{PH}$ in absorb process, lime/limestone increases free calcium concentration in aqueous solution to assimilate $\mathrm{SO}_{2} / \mathrm{SO}_{3}$ in gas 
phase [4]. Nevertheless, calcium bisulfite is formed under excess low PH to make the erosion of equipment more serious.

Wrap in oxidation process. The calcium sulfite and calcium sulfate are both insoluble solids [5], therefore, oxidation of calcium sulfite is a gas-liquid-solid three phase reaction system controlled by particle diffusion. Therefore, the main reaction in this process is transform of calcium sulfite to calcium sulfate on particle surface which needs a high PH to form loose calcium sulfate;

Effect of impurities. Compared with flue gas in thermal power plant, sintering flue gas has characteristics of high content of impurities (fluorine, chlorine, sodium, copper, arsenic, nickel, cobalt and so on) and complex compositions, etc [6]. These impurities will delay(fluorine, chlorine, arsenic) or accelerate (nickel, cobalt) the oxidation process, which will cause a low desulfurization rate or low utilization rate of raw material;

High energy consumption. The particle size of limestone/lime will be more than 325 mesh to avoid excessive package of gypsum and improve calcium concentration in slurry during spray. Moreover, high energy consumption in crushing and filtering for high water content in gypsum;

A large amount of solid waste. For defects above of this process, a large amount of solid waste produced. Besides, the waste is difficult to utilize for high content of impurities, which is easy to form secondary pollutants.

\section{Reasons for Calcium Sulfite Oxidation in Wet Flue Gas Desulfurization Process}

In the wet flue gas desulfurization process, part of calcium sulfite will precipitate as $\mathrm{CaSO}_{3} \bullet 1 / 2 \mathrm{H}_{2} \mathrm{O}$ if calcium sulfate failed to fully oxidized, and excess calcium sulfate in gypsum can not meet the requirements of cement production[7]. Because the effective composition of desulfurization gypsum is $\mathrm{CaSO}_{4} \cdot 2 \mathrm{H}_{2} \mathrm{O}$, when there is a certain amount of calcium sulfate in FGD gypsum, it is easy to lead to make calcium sulfate decomposed as $\mathrm{H} 2 \mathrm{SO} 4$ or $\mathrm{H}_{2} \mathrm{SO}_{3}$ which not only causes corrosion of equipment, but also affects the normal performance of cement [8]. Through the field investigation it is found that $\mathrm{pH}$ value of absorption solution is an important factor that affects oxidation of $\mathrm{CaSO}_{3}$. On the one hand, $\mathrm{pH}$ value shows effect on the absorption rate of $\mathrm{SO}_{2}$. The higher the $\mathrm{pH}$ value is, the faster the absorption process of $\mathrm{SO}_{2}$ will be. Because a high $\mathrm{PH}$ value increases the mass transfer coefficient, and promotes the desulfurization rate [9]. However, it is not conducive to dissolution of limestone and also causes the serious corrosion of system devices. A low $\mathrm{pH}$ value, although in favor of dissolution of limestone, will make $\mathrm{SO}_{2}$ absorption rate decline. On the other hand, $\mathrm{pH}$ value makes a difference to oxidation process of calcium sulfite. The oxidation rate of calcium sulfite is higher if $\mathrm{PH}$ value in the range of 3.5 to 5.4. As a result, it is significantly important for the desulfurization process to determine the appropriate $\mathrm{PH}$ value.

\subsection{The effect of $\mathrm{pH}$ on the dissolution of lime.}

The lime dissolution rate increases exponentially with the decrease of $\mathrm{pH}$ value. For example, the dissolution rate of $\mathrm{PH}$ value 4 is 5 times faster of that of $\mathrm{PH}$ value 6 . Data shows that when the $\mathrm{pH}$ is greater than a certain value, the utilization rate of lime will decline sharply, which is related to type and fineness of lime. While the lime is used as desulfurizer, the $\mathrm{pH}$ value may be relatively high due to the formation of $\mathrm{Ca}(\mathrm{OH})_{2}$ whose solubility is higher , the $\mathrm{pH}$ value ranges from 5.5 to 6.5.

\subsection{Effect of $\mathrm{pH}$ value on the efficiency of desulfurization.}

The $\mathrm{pH}$ value directly affects the absorption rate of SO2. The higher the $\mathrm{pH}$ value, the larger the total mass transfer coefficient value $\mathrm{K}$ will be, and the absorption rate is also higher. Improving the $\mathrm{pH}$ value of absorption liquid, which can not only improves the concentration of alkaline substances dissolved in the absorption solution, but also increase the concentration of alkaline substances hardly dissolved in the alkaline substances[10]. when dissolved alkaline substances runs out, hardly dissolved one dissolve in time so as to maintain sufficient alkalinity of liquid. Actually, high $\mathrm{pH}$ value leads to calcium left which is uneconomical. Analysis shows slurry fail to desulfurization when PH value is less than 4 . 


\subsection{The effect of $\mathrm{pH}$ on the oxidation of $\mathrm{CaSO}_{3}$}

When $\mathrm{pH}$ value ranges from 3.5 to 5.4 , the oxidation rate of sulfite is higher, and if the $\mathrm{pH}$ value is more than 5.5, the oxidation rate decreases rapidly, so low $\mathrm{pH}$ value is beneficial to oxidation of sulfite. In the spray tower, when $\mathrm{pH}$ ranges from 4.9 to 5.1 and molar ratio of oxygen and sulfur dioxide equals 2 , the oxidation rate achieves 95\%; when the $\mathrm{pH}$ value is more than 5.3 and the rate gets 95\% when molar ratio of oxygen and sulfur dioxide equals 3 [11].

Therefore, selecting the appropriate $\mathrm{pH}$ value of absorption solution is the key to the solution of calcium sulfite oxidation problem in wet flue gas desulfurization system. Combined with the actual operation of a metallurgical enterprise, when the $\mathrm{pH}$ value changes from 7.5 to a range of 5.3-5.8, it causes decline of desulfurization rate and difficult dehydration of desulfurization gypsum. It is urgent to solve problem that how to improve desulfurization efficiency and desulfurization gypsum quality in a low $\mathrm{pH}$ environment $(\mathrm{pH}=5.3-5.8)$.

\section{Solutions for Oxidation of Calcium Sulfite in Wet Flue Gas Desulfurization}

The key of applying sintering flue gas desulfurization gypsum in cement production is transforming $\mathrm{CaSO}_{3}$ to $\mathrm{CaSO}_{4}$ and getting $\mathrm{CaSO}_{4}$ into $\mathrm{CaSO}_{4} \cdot 2 \mathrm{H}_{2} \mathrm{O}$.

Measures for transforming $\mathrm{CaSO}_{3}$ to $\mathrm{CaSO}_{4}$. Oxygen content in flue gas directly affects oxidation rate of calcium sulfite. Therefore, in order to promote the desulfurization gypsum quality and reduce the content of $\mathrm{CaSO} 3$ in gypsum, increasing the oxidation fans is necessary.

\subsection{Adjusting PH value of absorb solution.}

The absorption liquid $\mathrm{pH}$ value was adjusted to 7.5 or so to improve the desulfurization rate and improve the dehydration of gypsum. However, the lime dosage increased and $\mathrm{CaSO}_{3}$ almost can hardly be oxidized under this condition resulting in the increase of content of $\mathrm{CaSO}_{3} \cdot 1 / 2 \mathrm{H}_{2} \mathrm{O}, \mathrm{CaO}$ and $\mathrm{Ca}(\mathrm{OH})_{2}$ in desulfurization gypsum and fail of desulfurization gypsum used in cement production. In addition, wet desulfurization equipment needs to operate in weak alkaline environment, otherwise, it will inevitably lead to corrosion of equipment. In order to solve problem of failure of the desulfurization gypsum used in cement production, the liquid $\mathrm{pH}$ value should be adjusted in the range of 5.3 to 5.8 to provide a good environment for the full oxidation of $\mathrm{CaSO} 3$.

\subsection{Increasing air flow rate.}

Oxygen directly involved in the process of flue gas desulfurization, which oxidized $\mathrm{CaSO}_{3}$ to $\mathrm{CaSO}_{4}$. with the increase of $\mathrm{O}_{2}$ content in flue gas, the formation of $\mathrm{CaSO}_{4} \cdot 2 \mathrm{H}_{2} \mathrm{O}$ speed up and the rate of desulfurization is also on the rise. Operation of more oxidation fans can improve the desulfurization rate, at the same time, it will lower the concentration of SO2 in flue gas.

Measures for transforming $\mathrm{CaSO}_{4}$ to $\mathrm{CaSO}_{4} \cdot 2 \mathrm{H}_{2} \mathrm{O}$ : The experiment shows that when $\mathrm{PH}$ value of slurry is no more than 6 , it will lead to the slurry dewatering difficulties, low dewatering efficiency and low desulfurization rate.According to the actual operation, factors that affect gypsum dewatering efficiency are mainly parameters of chemical reactions in tower and operation of dewatering system. The former is control of the crystallinity of $\mathrm{CaSO} 4$ and the latter is dehydration equipment.

\subsection{The addition of seed crystal.}

The parameters as PH value of absorption liquid, slurry density, liquid level of absorption tower, air flow rate and so on show direct effect on the crystallization of gypsum and dehydration. If controlled imperfectly, it will generate layered and needle like crystal, even for cluster or petal shape which is difficult to grow up and dehydrate for its high viscosity. In addition, impurities of smaller particle like dust and other substances such as lime free from the gypsum crystal, which is very easy to plug the dehydrator filter cloth, and lead to the difficulty of dehydration. In order to increase the crystal level, adding the $\mathrm{CaSO} 4 \cdot 2 \mathrm{H} 2 \mathrm{O}$ seeds was used to improve $\mathrm{CaSO} 4 \cdot 2 \mathrm{H} 2 \mathrm{O}$ crystallization and promote the performance of gypsum dehydration.

\subsection{Oxidation crystallization outside of tower.}

Considering the effect of reaction time, air amount and other operating parameters in absorption tower, the middle tank can be used to extend the oxidation and crystallization time. If necessary, adding flocculant is an alternative to make crystal grow up quickly, easy to dehydration. 


\subsection{Adjusting slurry density.}

Slurry saturation in absorber reflects saturation of gypsum. If density of gypsum slurry is low, it shows that the content of gypsum absorption tower is low and there are still plenty of calcium oxide existing. If the gypsum slurry discharges to outside of tower, it will lead to an increase in the content of calcium oxide in gypsum, which is not only a waste, but also lower the quality of gypsum; the high slurry density implies that calcium oxide and gypsum are excessive. Excessive calcium sulfate is not conducive to the absorption of SO2 and the dissolution of calcium oxide. Furthermore, it will cause difficulty of dehydration due to small particle size.

\section{Summary}

Through analysis on oxidation of $\mathrm{CaSO}_{3}$ and comprehensive utilization of desulfurization gypsum, solutions for problems above have been put forward. With more emphasis on environmental protection, the metallurgical enterprise should invest more capital and get more techicians to get involved in the sintering flue gas desulfurization process to meet the demand of environment standard. At the same time, experience in other industries is also significant to learn for a better development of metallurgical enterprises.

\section{Acknowledgements}

This paper was financially supported by Industrialization project of Shaanxi Provincial Education Department (15JF022), Industrial project of Shaanxi Province (2016GY-020) and Jinchuan - Xi'an university of architecture and technology research foundation (YY1405).

\section{References}

[1] MO J, WU Z, CHENG C, et al. Oxidation inhibition of sulfite in dual alkali flue gas desulfurization system [J]. Journal of Environmental Sciences, 2007, 19(2): 226-231.

[2] Jia Y, Zhong Q, Fan X, et al. Kinetics of oxidation of total sulfite in the ammonia-based wet flue gas desulfurization process [J]. Chemical Engineering Journal, 2010, 164(1): 132-138.

[3] Kallinikos L E, Farsari E I, Spartinos D N, et al. Simulation of the operation of an industrial wet flue gas desulfurization system[J]. Fuel Processing Technology, 2010, 91(12): 1794-1802.

[4] Wang L, Zhao Y. Kinetics of sulfite oxidation in wet desulfurization with catalyst of organic acid[J]. chemical engineering journal, 2008, 136(2): 221-226.

[5] Xiang G, Rui-tang G, Hong-lei D, et al. Dissolution rate of limestone for wet flue gas desulfurization in the presence of sulfite[J]. Journal of hazardous materials, 2009, 168(2): 1059-1064. [6] Hlincik T, Buryan P. Desulfurization of boiler flue gas by means of activated calcium oxide[J]. Fuel Processing Technology, 2013, 111: 62-67.

[7] Xiang G, Wang H, ZHONG Y, et al. Effects of magnesium and ferric ions on crystallization of calcium sulfate dihydrate under the simulated conditions of wet flue-gas desulfurization [J]. Chemical Research in Chinese Universities, 2008, 24(6): 688-693

[8] Zhou Y, Zhu X, Peng J, et al. The effect of hydrogen peroxide solution on SO2 removal in the semidry flue gas desulfurization process[J]. Journal of hazardous materials, 2009, 170(1): 436-442

[9] Tanaka H, Okino S, Tao K. Method for controlling the oxidation of sulfites in a flue gas desulfurization process: U.S. Patent 5,766,563[P]. 1998-6-16

[10] Yang L, Bao J, Yan J, et al. Removal of fine particles in wet flue gas desulfurization system by heterogeneous condensation[J]. Chemical engineering journal, 2010, 156(1): 25-32.

[11] Bigham J M, Kost D A, Stehouwer R C, et al. Mineralogical and engineering characteristics of dry flue gas desulfurization products[J]. Fuel, 2005, 84(14): 1839-1848. 